\title{
JURA: a collaborative solution to Hong Kong academic libraries storage challenge
}

\author{
Peter Sidorko \\ University Librarian \\ The University of Hong Kong \\ Linda Lee \\ JULAC Manager \\ Joint University Librarians Advisory Committee
}

\begin{abstract}
The purpose of this paper is to explore issues and challenges facing collaborative storage in Hong Kong academic libraries through the establishment of JURA, the Joint Universities Research Archive, an incorporated company of JULAC, the Joint University Librarians Advisory Committee, comprised of the 8 university libraries funded by the University Grants Committee in Hong Kong.
\end{abstract}

Viewed from the perspectives of the JURA Working Group and the authors, the establishment of a joint storage solution was deemed the most practical and cost effective means of reducing duplication of effort by providing efficient delivery of low use print collections to solve the problem of space limitations that are so rampant among Hong Kong's academic libraries.

This paper will begin with a background to the decision of a joint storage facility, the progress and likely future developments, and a range of related problems and issues on perspectives of collaborative or cooperative storage, issues of long term storage, and service benefits to be realized. A review of the JURA project and how this collaborative approach may impact Hong Kong's higher education libraries, specifically by investigating the unique possibilities for the future management of these resources, will also be covered. The authors will also use examples of existing case studies in the UK, United States and Australia to illustrate their points.

\section{JULAC Libraries}

The Joint University Librarians Advisory Committee (JULAC) in Hong Kong was established in 1967 by the Heads of Universities Committee (HUCOM). It is a forum to discuss, coordinate, and collaborate on library information resources and services among the libraries of the eight tertiary education institutions funded by the University Grants Committee (UGC) of the Hong Kong SAR Government.

Member libraries include The Chinese University of Hong Kong, City University of Hong Kong, The Hong Kong Baptist University, The Hong Kong Institute of Education, 
The Hong Kong Polytechnic University, The Hong Kong University of Science and Technology, Lingnan University and The University of Hong Kong.

\section{Planning for JURA}

The printed book and journal show little signs of disappearing. According to Nielsen BookScan, the publishing industry standard for book sales data, book sales remain healthy. In 2001, 162 million books were sold in Britain. A decade later in 2010, in which the "internet bloomed, online gaming exploded, television channels proliferated, digital piracy rampaged and, latterly, recession gloomed”, there were 229 million books sold. A remarkable $42 \%$ increase in the number of books sold over the last 10 years as reported by Lloyd Shepherd (2011).

Although publishing trends show preference for printed items will be diminishing in the next few years as more and more information will be digitized, a large portion of the library collection will still be in print version. American College and Research Libraries (2012) in its report highlighted the patron drive e-book acquisition as one of the top 10 trends of academic libraries. Additionally, many libraries will move large collections of physical books in open stacks to low use storage to free up space for the creation of learning spaces and other services.

In 2003, JULAC started its initial planning for a joint storage building. At meetings facilitated by consultants, various comments and suggestions on establishing a central storage facility for JULAC member libraries were discussed. JULAC libraries statistics show that current purchasing trends for the JULAC libraries for print monographs and print journals is slightly declining or maintaining the same growth for the past few years, while e-materials purchasing are on a steady increase. Furthermore, Hong Kong academic library users show increasing preference for e-resources. In 2010, The University of Hong Kong Libraries conducted a biennial survey on their users and the data collected clearly indicated users' preference for e-journals over print has increased from 59\% in 2006 to 66.4\%, similarly users' preference for e-books over print changed from $22.7 \%$ to $45.1 \%$ for the same period.

Greenstein (2009), Vice Provost for Academic Planning and Programs at the University of California System indicated that within the decade, groups of universities will have shared print and digital repositories where they store books they no longer care to manage. "There are national discussions about how and to what extent we can begin to collaborate institutionally to share the cost of storing and managing books," he said. "That trend should keeping continuing as capital funding is scarce, as space constraints are severe, especially on urban campuses - and, frankly, as funding needs to flow into other aspects of the academic program.”

It became evident that a collaborative (share collection) and cooperative (share space) partnering approach would be a relatively low risk solution for the initiation of a joint storage. Conducting a feasibility study on constructing a central storage facility would be the initial step to a successful large scale implementation.

The central depository should also be cautioned not to become a "dumping ground" of items that participating libraries do not want to keep in their circulating collections, hence a charged scheme was suggested. Members ultimately accepted the concept of a 
"single-copy" depository with items retrievable for circulation. While adopting the concept of "single-copy" and "last-copy" storage with "shared ownership" by all UGC institutions, there would be a need to undertake a de-duplication exercise for the resources and collections among all JULAC members. The extra and duplicate copies would be donated to the institutions of higher learning in China or to other worthy destinations.

A need to set up a governing board with legal status and a budget for operation of the storage, such as $100 \%$ funding from the Government or funding shared by each library was discussed. Concerns and issues of disaster management and resource sharing of the central storage were also addressed.

Numerous benefits of creating a central storage were highlighted during the initial planning stage, including the cost benefit factor to justify the establishment of a central storage facility as opposed to doing it individually by each JULAC member library. As shown in many other cases, the building of a new library or extension usually costs several times more than an off-site storage facility and this cost is severely exacerbated when the need is required 8 times over.

\section{JURA Proposed Governance and Funding}

As a result of continuing space issues, with the support of the Heads of Universities Committee (HUCOM) a submission was made in 2008 to the University Grants Committee (UGC) to seek funding for a preliminary study to determine the best model for a collaborative storage and delivery service for valuable but lower-use materials held in JULAC libraries.

With the endorsement from HUCOM, the Joint University Research Archive (JURA) was established, together with the initiation of two high level committees. The first of these, the JURA Project Committee (JPC), was established to ensure that the storage facility is fit for the purpose required and to achieve the building of the JURA facility to specification. The second committee, the JURA Working Group (JWG), was established to operate as the current management of the library specific tasks to prepare and deliver the JURA collection for JURA storage; develop procedures, work tools and methods required for JURA's operations; and to help the JPC see the project through to its conclusion. The University of Hong Kong was chosen as the Lead Institution, responsible for the overall management of the JURA project.

Funding was allocated to employ consultants for the purpose of the initial planning stage to assist the libraries to define, prepare JURA processes and policies; develop a stakeholder communications plan; give input to project procurement tenders; establish de-duplication procedures and to work on a JURA Operations Manual. The JURA Operating Principles, De-duplication procedures and the proposed Virtual JURA Methodology documents were drafted and ready for execution. The model agreed upon mirrored the CASS (Nicholson, 2005) model as one of joint ownership, de-duplication of material, and management by a new body representing the stakeholders.

The Governance Structure for the Joint Universities Research Archive (JURA) is by the incorporation of a company to run the storage facility. Its mission is to provide Hong Kong's JULAC libraries with an efficient, sustainable and secure climate-controlled 
storage and retrieval facility for research materials that promotes shared access to scholarly information and facilitates the effective use of space within existing library buildings.

JULAC Joint Universities Research Archive Limited is an incorporated company with liability by guarantee set up by the eight participating institutions and managed by a Board of Directors being the 8 JULAC librarians. The company is registered as a charitable organization for tax planning purpose and to accommodate future fund raising efforts.

\section{Benefits of collaborative storage}

Libraries are renowned for their ability to work together in relative harmony in order to achieve common goals. Joint purchasing is one such example that is common among consortia worldwide. The benefits of such collaboration are obvious in the form of financial savings but also in the degree of staff efforts. Administrative and funding bodies recognise such benefits and encourage libraries to work together towards common goals in the interests of financial and human efficiencies. The situation is no different in Hong Kong.

Past efforts by the University Grants Committee, including financial motivation, to encourage "deep collaboration" among the 8 institutions has left the UGC "in general, disappointed at the level of collaboration" (University Grants Committee, 2010). The same report, however, identified "areas of success: ... the collaboration by libraries on a new joint storage facility and sharing of books. Institutions can and should build on these successes” (ibid).

Financial and human efficiencies are not the only reasons for a collaborative approach to storage. The sheer scale of building 8 repositories each with most likely different modes of operation, different rules for usage and different staffing profiles would mean that the ease with which resources could be shared would be limited.

But there are also limitations to collaborative approaches. Verzosa (2004) states that the typical obstacles to collaboration as being

"rivalry and competition, mistrust and jealousy, politics and personalities, different institutional priorities and indifferent institutional administrators, unequal development and parochialism ... negative attitudes, such as skepticism, fear of loss, reluctance to take risks, and the pervasive lack of tradition of cooperation”

While Verzosa's statement was referring to attitudes in South East Asia and in particular, the Philippines, there are still elements of these concerns that apply to the Hong Kong environment, even with its long standing tradition of successful collaboration among the UGC libraries. In the context of JURA there are a number of issues that raise concerns: the management and decision making issues related to the facility; the ownership of the collection; the reduced physical volume count of each of the 8 libraries, and; the costs associated with the facility and the distribution of these costs, to name just a few. 
As all UGC institutions are and will be under financial constraints in the next few years, members would be charged for renting space to meet their individual storage needs, thus it is financially beneficial to all UGC institutions to build one central storage facility. The benefit of setting up a governing board with legal status and a budget for operation of the facility, such as funding shared by each library, will be advocated and will ensure that an equitable approach towards governance will be achieved.

As Nicholson (2005) pointed out that with little capital investment in new library building, many libraries released space by storing lesser-used materials. These materials are no longer critical to the institutional mission but are of continuing value to researchers in closed access, sometimes in less than ideal environmental conditions. While these items may generate little usage, we are nonetheless committed to maintain them for future generations of Hong Kong, indeed all, scholars.

JURA objectives, while well-defined in order to persuade the HUCOM management of the need for a central remote/off-site storage facility may not seem as pressing an issue at present to some JULAC member libraries. However, statistics show that there will be a future and genuine need for most of the member libraries in 3-5 years' time. Statistical compilation through projection of collection growth and calculation of space needs among all JULAC member libraries were analysed to support the argument of high density storage. In addition, recommendations were drawn from the Kaiser Report (2006) to justify the needs and support for requesting additional library space allocation.

JURA builds upon the successful sharing of resources through the Hong Kong Academic Library Link (HKALL), an accelerated resource sharing and a union catalogue (utilising Innovative's Inn-Reach module) allowing the students and staff of the eight partner institutions to search and access a collection of over 8 million titles of monographs (11M+ volumes) held in the eight participating libraries. A recent analysis (October 2012) of the catalogue reveals that over $73 \%$ of the titles in the catalogue are unique. This is deemed to be extremely high and is indicative that, for at least monographs, our collections are complementary rather than highly replicated suggesting a high number of monographs will find their way into JURA.

JURA is also noteworthy because it will create the largest single historical archive of western research materials in Asia and will become an unrivalled centre for scholarship and research. It will employ technology that will reduce the cost of maintaining access to an important and large amount of information acquired over the course of decades. It will consequently enable each of the eight libraries to free space for other purposes and services.

JURA will use advanced Automatic Retrieval System (ARS) technology to provide rapid access to articles from older remotely-stored journals. It will reduce the per volume cost of permanently storing these research materials in an optimal and preservation-sound environment. JURA will strengthen the research material support provided to all of Hong Kong's students and staff while allowing the libraries at each institution to continue to support their unique roles and missions. In addition, JURA will provide the potential for greater exposure to the resources housed in the facility through better indexing, metadata, table of contents and even digitisation (scan on demand). 


\section{Different Storage Systems}

A study was conducted based on preliminary investigative work undertaken by JULAC in consultation with Hamlet Management Ltd., a firm specializing in library building and storage solutions. As a part of the initial investigation in 2005, the JULAC libraries identified different storage systems by comparing the initial cost, human effort, construction and operation, the pros and cons of each storage system.

\section{Traditional shelving (Box shelving)}

Total set up cost is low as renovation of an existing building is feasible, while a relatively traditional construction method can be adopted. This system uses the least mechanical means for shelving and retrieval, and books are stored in open shelves, with good air flow through the stored items for book preservation.

However, the construction would require a relatively larger building area and high human effort is needed for shelving and retrieval. Heavy weight handling of boxes for each shelving and retrieval process is required and human errors may occur in placement of items.

\section{Traditional shelving (Spine out shelving)}

Total set up cost is high due to construction costs over a longer period of time, as investment cost on electrical and mechanical systems (E\&M), furniture, fixtures \& equipment (FF\&E) cost is the highest among all cases. The system needs the largest total building area. Annual expense of the system is high, as high human effort is need for shelving and retrieval. Human errors may occur in placement of items.

However, renovation of an existing building is feasible and traditional construction methods can be adopted. This system also uses low mechanical means for shelving and retrieval. There will be light weight handling for each shelving and retrieval process. As books are stored in open shelves, the air flow through the stored items is good for book preservation.

\section{Compact shelving}

Construction costs and maintenance costs of the building are low, compared with traditional shelving. The maintenance cost of the bookshelves is higher. Renovation of an existing building is feasible; this system enjoys high storage to floor area efficiency with a shorter period of construction. Human errors may occur in placement of items. High human effort is needed for shelving and retrieval. Air flow through the stored items is restricted by the closely packed bays of shelves.

\section{| Harvard / Stanford (Hierarchical storage) method in multi-story building}

Total set up cost and total annual expense is the lowest among the 7 models. Less building footprint area is needed and a shorter period of construction is required. As the picking process is partly operated by machines (cherry picker vehicles), moderate human effort is needed for operation. Air flow through the stored items is good for book preservation.

High head room and heavy or low loading is needed for the shelves. Renovation of existing buildings to suit the system is not feasible. There is a need to rely on the quality and durability of the cherry picker vehicles. Mechanical faults may occur. Time for 
shelving and retrieval is longer. Heavy weight handling of boxes for each pick up and retrieval process is to be considered. The potential liability for industrial accidents when accessing high levels and operating the cherry picker machines is a further consideration.

\section{Harvard / Stanford (Hierarchical storage) method in single story building}

Set up cost is the lowest for all systems with a single story and a shorter period of construction is required. Still need the picking process operated by machines but moderate human effort is needed for operation. Air flow through the stored items is good for book preservation.

A large site area is required. High head room and heavy or low loading is needed for the shelves. Renovation of existing buildings to suit the system is not feasible. Reliability of the quality of the cherry picker vehicles is a concern. Mechanical faults may occur. Time for shelving and retrieval is longer. Heavy weight handling of boxes for each pick up and retrieval process is to be considered. There may be potential liability for industrial accidents when accessing high levels and operating the cherry picker machines.

\section{Automatic storage and retrieval system in multi-story building}

Operation cost of E\&M systems is the lowest among the 7 models. The smallest building area and stored items can be tracked. Stored items can be tracked automatically and picked up fast. The computerized system also allows easy management.

As the process of picking up the stored materials is done by machines, human effort can be greatly reduced. The computerized system also encourages people to use the storage centre and borrow the materials from the centre more frequently because of its speed and convenience. Quick access and retrieval of material can be scanned and transmitted electronically to end users in short time.

Total set up costs are the highest among the systems. High head room height and heavy floor loading is needed for the shelves. Renovation of existing buildings to suit the system is not feasible. A steel structure is necessary to withstand the extremely high live load. Reliability of the quality of the robotic system is a concern. The system greatly depends on machines and computer systems. Therefore, if there is any failure in electrical or computer systems, it cannot function.

\section{Automatic storage and retrieval system in single story building}

This system is competitively costed compared to other systems with the smallest building area and a shorter period of construction needed. Stored items can be tracked automatically and picked up fast. The computerized system also allows easy management. As the process of picking up the stored materials is done by machines, human effort can be greatly reduced.

The cost of construction is higher than Harvard / Stanford system in single story configuration. High head room height and heavy floor loading is needed for the shelves. Renovation of existing buildings to suit the system is not feasible. Reliability of the quality of the robotic system is a concern. The system greatly depends on machines and computer systems. Therefore, if there is any failure in electrical or computer systems, it cannot function. 
In supporting the rationale behind the conceptual design of the proposed JURA storage facility, a number of site visits were conducted to Australia and North America to investigate the different storage systems in these countries. As a consequence to the visits, the directors of Hong Kong's eight academic libraries began to contemplate that a collaborative solution to their common problem was the most optimal of possibilities.

The table below summarizes the storage systems of libraries in Australia and North America and their method of storing large volumes of library materials as a result of the site visits:

\begin{tabular}{|c|c|c|}
\hline Location & Method of book storage & Build shell \\
\hline \multicolumn{3}{|l|}{ Australia } \\
\hline $\begin{array}{l}\text { The University of Melbourne } \\
\text { Archives }\end{array}$ & Open mesh - Boxed packing & Converted warehouse \\
\hline $\begin{array}{l}\text { State Library of Victoria Ballarat } \\
\text { Store, University of Ballarat }\end{array}$ & Open mesh & Purpose built \\
\hline $\begin{array}{l}\text { Centre for Archival Materials } \\
\text { (CARM), LaTrobe University }\end{array}$ & Open mesh - Boxed packing & Purpose built \\
\hline $\begin{array}{l}\text { Knowledge Resource Centre, Dept. } \\
\text { of Primary Industries, Victoria }\end{array}$ & $\begin{array}{l}\text { Open mesh - Spine out } \\
\text { shelving }\end{array}$ & Purpose built \\
\hline \multicolumn{3}{|l|}{ North America } \\
\hline $\begin{array}{l}\text { Northern California Repository, } \\
\text { California }\end{array}$ & $\begin{array}{l}\text { Regular shelving \& Compact } \\
\text { shelving }\end{array}$ & $\begin{array}{l}\text { Partially converted from } \\
\text { existing building and } \\
\text { partially purpose built }\end{array}$ \\
\hline $\begin{array}{l}\text { Sonoma California State University, } \\
\text { California }\end{array}$ & $\begin{array}{l}\text { Automatic storage and } \\
\text { retrieval system - Boxed } \\
\text { packing }\end{array}$ & Purpose built \\
\hline $\begin{array}{l}\text { Lied Library, University of Nevada, } \\
\text { Las Vegas (UNLV) }\end{array}$ & $\begin{array}{l}\text { Automatic storage and } \\
\text { retrieval system - Boxed } \\
\text { packing }\end{array}$ & Purpose built \\
\hline $\begin{array}{l}\text { University of British Columbia, } \\
\text { Canada }\end{array}$ & $\begin{array}{l}\text { Automatic storage and } \\
\text { retrieval system - Boxed } \\
\text { packing }\end{array}$ & Purpose built \\
\hline Stanford University & $\begin{array}{l}\text { Harvard / Stanford } \\
\text { Hierarchical storage method }\end{array}$ & Purpose built \\
\hline
\end{tabular}

\section{JURA Central Storage Facility Proposal}

Hamlet (2007) reported that the libraries at Hong Kong's eight UGC supported universities have both a challenge and an opportunity. The challenge is insufficient space to safely preserve the rich information resources that have been, and will continue to be collected up through the end of the next decade. The opportunity is to collaborate with each other to build a state-of-the-art research archive for the millions of volumes for which they do not and will not have space. This facility will support the research 
needs of Hong Kong's students and teachers, will serve as an iconic representation of what can happen when competing institutions collaborate deeply, and will become a visible reminder that our information society is composed of both our print past and present, and our digital present and future.

To accomplish these purposes and following analysis of the case studies of the different storage systems and the site visits, Hong Kong's eight JULAC libraries recommended that a multi-story Automated Retrieval System (ARS) storage facility be constructed. This recommendation was based on reasonable building costs, operation cost of E\&M is the lowest with a smallest building area and stored items can be tracked, which will help guarantee the Archive's long-term sustainability.

The design for the JURA facility consists of a main building block with 3 floors each of $13.85 \mathrm{~m}$ high, which is primarily for housing the ASRS storage space and a small building block mainly for the administration office and E\&M plant rooms. The total construction floor area is approx. $9000 \mathrm{~m} 2$ and there will be provision for a fourth floor for expansion in the future. The estimated storage capacity is 5.27 million books now and 8.432 million books after expansion. The general building plan has been approved by the government.

The building structure is a reinforced concrete beam and slab system which has allowed for the future addition of an extra floor of $13.8 \mathrm{~m}$ height and the non-percussive mini piles is adopted as the foundation as it is most economical. Extensive site formation work involving the construction of the new road had been approved by government and the traffic impact assessment had also been given approval. Conventional all air system involving the use of air handling unit with variable speed drive is adopted as the Air Conditioning and Mechanical Ventilating System (ACMV) system. Regarding the fire services system, an unprecedented early suppression fast response sprinkler type is selected which can best maximize the storage capacity of the building. The project adopts Leadership in Energy and Environmental Design (LEED) accreditation system protocols and preliminary assessment indicates that it is likely to be eligible for silver rating minimum. Subject to extra funding, a Gold rating is highly probable as well.

JURA appointed the Arup company as Project Manager for the JURA Project in May 2010 for Stage 1 of the project which covers the inception, feasibility study, proposal and detailed design of the building. The architectural consultants carefully studied the question of whether it would be advantageous to renovate an existing building or to construct a new facility. They concluded that while it might be possible in a renovated building, they found that the construction of a purpose-built facility was preferred for several reasons:

i. It costs more to renovate an existing building than to build a new one (50 to $80 \%$ higher).

ii. The cost for an existing building includes the cost of the expensive land premium whereas it is assumed that the land would be contributed at no cost to the project for a new building by the Government.

iii. It is quite likely that when an existing building is acquired, more land, and potentially more building, than is necessary will have to be purchased.

\section{JURA Business Plan}


The Business Plan for the establishment and management of the Joint University Research Archive (JURA) is based upon the outcomes of a quantity survey and a landuse feasibility study, both commissioned by the University of Hong Kong Libraries on behalf of JULAC. According to the data collected, all JULAC libraries anticipate that their print collections will exceed available capacity within their libraries in the next one to three years, at current rates of acquisitions. This situation will continue to worsen for a number of these libraries until a long-term solution is established, as they are dealing with not only the problem of housing growing collections, but also of finding space to provide new services and facilities to meet the changing demands of student library usage. By pooling these materials into a central facility, each library is able to offer its constituent staff and students' access to a vast collection of research materials, while at the same time releasing floor space in the libraries for other services and resources.

The JURA Business Plan has a number of recommendations. Firstly, it outlines the challenge of insufficient space to house anticipated future collection growth and concludes that a joint research archive will not only address this problem, but will also insure that research materials are held in perpetuity for the benefit of future generations of students and scholars. Secondly, it evaluates the main possible storage options from establishment, operating costs, and preservation and retrieval points of view. Thirdly, it concludes that looking at the situation from all of these perspectives, an automated retrieval system (ARS) in a multi-story purpose-built facility provides the "best-fit" solution. Fourthly, it incorporates a statement of "operating principles" which demonstrates how JULAC will manage the facility. The fundamental operating principle will be that JULAC will jointly manage and fund the facility through a "Governing Authority" which will be incorporated as a company within the Hong Kong SAR, and which will include the JULAC members on the Board of Directors. It is anticipated that as an efficiency measure, JULAC will out-source the day-to-day management of the facility to one of the eight libraries or to an outside third party. Lastly, it includes a financial statement which sets out both the start-up and on-going operating costs of JURA, based on the recommendation for a multi-storey ARS facility. While UGC funds are sought for the initial establishment of the facility, it is anticipated that JULAC will jointly fund the operating costs, based on a formula which acknowledges the different levels of funding of each JULAC library and the differing levels of use that each library may make of the facility.

In order to develop a proposal for the sharing of the operating costs of the planned JURA facility among the eight member institutions, with fairness as the basic principle and with particular attention to the:

a. comparative size and operational scale of each member institution

b. number of books to be stored by each member institution.

c. ways to accord ownership if there are multiple copies of the same book

d. principles for the determining of user costs,

JULAC has developed a formula taking into account the following principles:

i. All member institutions are to share equally at least part of the recurrent costs of the facility; 
ii. Member institutions are to support the costs of the facility in part according to the relative size of their institutions and taking into consideration the potential number of users at each institution.

iii. Member institutions are also to support the costs of the facility in part according to the relative number of volumes each library is projecting to deposit in the Archive.

The Business Plan concludes with a request to the UGC for funding for the establishment costs of the facility. Hand in hand with this proposal, an allocation of a 13,500 square metre site of Government land, recommended as part of the land-use study is also requested, to house the facility in the recommended configuration. Subsequent recurrent costs will be provided by the eight JULAC libraries annually. In October 2012, the land for building JURA central storage was approved in-principle from the District Land Conference (DLC) following JURA’s Incorporation.

\section{Conclusion}

Seaman (2005) in his reviews of collaboratively managing a high-density remote storage facility for four Colorado institutions - the University of Colorado at Boulder, the University of Colorado at Denver, the University of Colorado Health Sciences Centre, and the University of Denver - states that

"this mix of public and private institutions agreed to collaborative collection management, including a no duplication policy and the granting of direct access to stored materials for nonparticipation institutions through a state-wide union catalogue. Ownership of stored materials, selection of items for storage, operational management, and online and physical access proved to be challenging policy issues requiring committees, patience, and compromise to resolve."

Pressures to cut back on book purchasing come not from a lack of titles but from a lack of funds as libraries are forced to allocate more resources to electronic resources and to cover the increasing costs of print journals. Although HKALL allows JULAC libraries to purchase fewer duplicate titles, it also allows those libraries to purchase other titles that are needed on their campus. Libraries may keep fewer back issues of journals and purchase more reference books in digital format. However, it is important to note that printed monographs are still, at least for now, the mainstay of scholarship and will most likely remain so for some years.. If the annual increase of 400,000 volumes by the 8 JULAC libraries each year will continue for at least the next 20 years, it is estimated that JURA will take 15 to 20 years to reach full capacity.

In the study of user involvement in the Open University library building project, Hunt (2008) agreed that the important elements of a project were the "consortium, the culture and tone, use of value management and risk management, teambuilding elements, communication, participation in the team by sub-contractors from an early stage, continuous improvement processes and project personnel”. The proposed new JURA joint storage will be a partnering project through deep collaboration and cooperation principles among its JULAC libraries, it will be a fully functional building for the right place, at the right time and for the right reasons as well as other factors contributing to the preliminary success of the planning executed so far due to the commitment by all 
JULAC libraries and their openness to achieve resolution with a clear project scope. The establishment of JURA and the process of realising JURA have the potential to be catalysts for change in Hong Kong academic libraries and indeed across the higher education sector. JURA will mark a new era in deep collaboration, it has the potential to strengthen commitment to collaboration among the eight libraries, to enhance and develop new strategic and operational goals and to set a high standard for all future collaborative efforts.

The future of the JURA joint facility is still unclear in terms of its funding from the government, which has reselected the project under the 2012 Capital Works Resource Allocation Exercise (CWRAE) as Category B-, that pre-construction works may commence but the project is not presently allowed to be submitted to the Legislative Council (LegCo) for final funding approval. We cannot predict what the subsequent 20 years will bring in terms of pressures for additional building at JULAC campuses, but we can expect that the pressure for new library building should come from the need to accommodate new services, rather than house lesser used research materials. Coupled with HKALL, JULAC libraries will be able to rationalize their collections for better management. And, more importantly still, future scholars in the region will be grateful to the foresight of those who preserved the materials they need for their research.

This paper has provided a background to the decision of a joint storage facility, the progress, issues, concerns and likely future developments. In addition, it has studied the options available for high density book storage solutions in North America and Australia. It also discusses the advantages and disadvantages of each in terms of operation efficiency of storage capacity, construction cost and operating cost. It compares the feasibility of purpose-built construction versus renovation of an existing building, and examines the cost implications and limitations on each in the context of suitable lands and buildings available in public and private sectors in the Hong Kong SAR. 


\section{$\underline{\text { References }}$}

American College Research Libraries. Research Planning and Review Committee (2012). 2012 top ten trends in academic libraries: a review of the trends and issues affecting academic libraries in higher education. College and Research Libraries News, June pp.311-320.

Greenstein, Daniel (2009). Libraries of the Future by Steve Kolowich. Inside Higher Ed. September 24. Available at http://www.insidehighered.com/news/2009/09/24/libraries (accessed on 13 March 2013).

Hong Kong. Joint University Librarians Advisory Committee (2006). Study of Joint University Research Archive in consultation with Mr Graeme Murphy of Hamlet Management Ltd.

Hong Kong. JULAC Joint University Research Archive. (2007). Business Plan January 26, 2007. Hamlet Management Pty Ltd and the Joint Storage Project Group.

Hong Kong. University Grants Committee (2010). "Aspirations for the Higher Education System in Hong Kong - Report of the University Grants Committee", available at: http://www.ugc.edu.hk/eng/ugc/publication/report/her2010/her2010.htm (accessed 19 March, 2013).

Hong Kong. University Grants Committee (2006). Review of space requirements formula and standards / Harvey $\mathrm{H}$. Kaiser Associates. Available at http://www.ugc.edu.hk/eng/doc/ugc/publication/other/2006/f06-13e.pdf (accessed 13 March 2013).

Hong Kong. The University of Hong Kong. Hong Kong Academic Library Link. Available at http://hkall.hku.hk/ (accessed on 8 March 2013).

Hunt, Mary (2008) User involvement in the Open University library building project. New Library World Vol. 109 no.3/4 pp.166-172.

Nicholson, Catherine M. (2005) CASS: a collaborative academic store for Scotland. Library Management Vol. 26, no. 1 / 2 pp. 32-41.

Nielsen Bookscan. Available at http://www.nielsenbookscan.co.uk/controller.php?page=48 (accessed on 13 March 2013).

Seaman, Scott (2005) Collaborative collection management in a high-density Storage Facility. College \& Research Libraries Vol. 66 no. 1 pp.20-27. Available at http://crl.acrl.org/content/66/1/20.short (accessed on 8 March 2013).

Shepherd, Lloyd (2011) The death of books has been greatly exaggerated. The Guardian 30 August. Available at http://www.guardian.co.uk/books/2011/aug/30/death-booksexaggerated (accessed 12 March 2013). 
Verzosa, Fe Angela M. (2004) The future of library cooperation in Southeast Asia. 2004 Asian Library and Information Conference (ALIC), 21 -24 November, 2004. Bangkok, Thailand, pp.7. 